\title{
Genetic Variability of Drought Adaptive Traits in Nepalese Wheat (Triticum aestivum L.) Germplasm
}

Dipendra Pokharel and Madhav Pandey

\begin{abstract}
Wheat (Triticum aestivum L.) is one of the major cereal crops vital for global food supply. Most of the wheat crop in developing world including that of Nepal is either grown with limited irrigation or under rainfed conditions and thus face moisture stress at one or more growth stages limiting grain yield. An experiment was carried out at the Institute of Agriculture and Animal Science, Rampur, Nepal, to evaluate the genetic variability of selected drought adaptive traits in Nepalese wheat germplasm. The wheat genotypes evaluated comprised of Nepalese landraces and commercial cultivars, CIMMYT (International Center for Maize and Wheat Improvement) derived advanced introduction lines and three checks with differential drought adaptability. The wheat genotypes were grown in pots (single plant) arranged in a replicated split plot design in greenhouse under two contrasting moisture regimes, optimum and moisture stressed. The genotypes were evaluated for water use, water use efficiency, relative leaf water content and biomass production. The ANOVA (Analysis of Variance) revealed significant variation between environments and among the wheat genotypes for most of the traits studied. A wide range of variability was observed for water use, water use efficiency, biomass yield and relative leaf water content in moisture stressed and non-stressed environments. Nepalese cultivar Gautam showed a number of favorable drought adaptive traits, whereas, Bhrikuti was average in this respect. Based on the scores of drought adaptive traits recently released Cultivar (cv). Vijay was characterized as drought sensitive. A number of landraces and advanced breeding lines showed high level of water use efficiency and other positive traits for drought adaptation.
\end{abstract}

Key words: Triticum aestivum L., landrace, water use efficiency, RWC, STI, drought stress

\section{Introduction}

Wheat (Triticum aestivum L.) is the most important cereal crop of the world providing staple food for about $35 \%$ of the world population. In the year 2009, 686 million tons of wheat grains were produced from about 226 million hectares of crop area, globally (FAOSTAT 2011). Wheat is the major staple in the IndoGangetic Plains of South Asia, a region comprising the plains of eastern India, southern Nepal, parts of Bangladesh and Pakistan. This region is regarded as a low-income region with a vast number of small and marginalized farmers. The area under wheat cultivation in this region is over 3.6 million ha which is around $16 \%$ of the global wheat area, producing nearly $15 \%$ of the global wheat (CIMMYT 2009). Wheat is a major cereal crop of Nepal. The total wheat area and production in Nepal for the year 2009 was estimated to be 0.73 million ha and 1.55 million tons, respectively, with an estimated yield of 2129 $\mathrm{kg} / \mathrm{ha}$ (MOAC 2010 ). The crop contributes $7.14 \%$ to the agricultural gross domestic products (MOAC 2010).

Moisture stress is one of the major abiotic factors limiting wheat production worldwide (Richards, Rebetzkel et al 2001). It is estimated that almost half the area sown to wheat in developing countries and up to $70 \%$ area in the developed countries suffer from periodic drought (Trethowan and Pfeiffer 2000). In a survey that covered 102 million hectares of wheat area in the developing world ( $47 \%$ global wheat area or $89 \%$ of the wheat area in developing countries) revealed moisture stress as one of the major constraints to wheat production with an estimated annual yield loss of 19 to $50 \%$ (Kosina, Reynolds et al 2007). Annual wheat yield loss of up to $15 \%$ has been reported due to drought stress in the UK (Foulkes, Sylvester-Bradley et al 2007).

In recent years, moisture stress is being considered a potential threat to wheat production in South Asia. In this region, wheat is largely sown under residual moisture after monsoon rains. Although some of the areas are well irrigated (mostly in India and Pakistan), a large acreage of wheat crop in the region is either partially irrigated or rainfed and therefore, face intermittent or terminal drought stress. Drought stress has been recognized as one of the major abiotic factors limiting wheat production in India (Joshi, Mishra et al 2007), Pakistan (Kisana, Hussain et al 2008) and Nepal (Bhatta, Sharma and Ortiz-Ferrara 2008). Due to increasing summer temperature, uneven annual rainfall pattern and depleting water resource for irrigation, breeding wheat for drought tolerance will become an increasingly higher priority in this region (Joshi, Mishra et al 2007). Thus, wheat breeding for drought tolerance or for higher water use efficiency is a topic of increasing concern. Drought tolerant wheat cultivars are not only required to sustain the existing wheat yields but also to ensure yield growth that is needed to supply food to the growing global population, especially in the developing world. The present study therefore aimed at assessing the genetic variability of drought adaptive traits in Nepalese wheat germplasm which is vital for the development of drought tolerant wheat cultivars.

\section{Materials and Methods}

The study was conducted in a Greenhouse at the Institute of Agriculture and Animal Science (IAAS), Rampur, Chitwan during the 2009/10 wheat season.

\section{Plant Material}

In total 60 spring wheat genotypes were evaluated that included 27 Nepalese landraces obtained from the Agricultural Botany Division, Nepal Agricultural Research Council (NARC), Khumaltar; 27 advanced breeding lines from the National Wheat Research Program (NWRP), NARC, Bhairahawa, three international check varieties 
namely, Dharwar Dry (drought tolerant cultivar), Hartog $^{1}$ (high yielding cv. for dry areas) and Seri M84, a high yielding CIMMYT developed cultivar. The seed samples of these three genotypes were kindly provided by Dr. John T. Christopher, Queensland Department of Primary Industries and Fisheries, Leslie Research Centre, Australia. In addition to this, three Nepalese commercial varieties- Gautam, Bhrikuti and Vijay were also included in the study. The details of the plant material used in the experiment are given in Table 1.

Experimental cycle was only up to flowering stage not to the full crop growth cycle. Further, experiment was each with a single plant grown in a pot.

\section{Experiment Design and Layout}

The experiment was laid out in a split plot design with optimum moisture and moisture stressed environments as main plot factors and 60 wheat genotypes as sub-plot factors. Each set of experiment was replicated three times. Plastic pots $(\mathrm{n}=360)$ of $12 \mathrm{~cm}$ (diameter) x $30 \mathrm{~cm}$ (depth) were used to grow single wheat plant. Each pot was filled with $7.5 \mathrm{~kg}$ of soil from a wheat field of the research block of agronomy farm (IAAS). The soil texture class was determined sandy loam and had moisture content about
$75 \%$ of the field capacity. Three seeds of each genotype were sown in respective pots and two seedlings were thinned out after three weeks keeping the most vigorous single plant in each pot. All the pots in moisture non-stressed experiment were watered regularly to maintain the initial soil moisture content; i.e., $7.5 \mathrm{~kg}$ soil weight. For moisture stressed experiment, soil moisture content was maintained at $35 \%$ of the field capacity (i.e., $6.5 \mathrm{~kg}$ soil weight) by withholding watering at tillering (growth stage 20, Zadok scale) until harvested at flowering stage (growth stage 60, Zadok scale). Evapo-transpiration was recorded for each pot regularly and the amount of water transpired by the plants was estimated based on six evaporation control pots randomly placed in the Greenhouse. Data were recorded on total water use (WU), water use efficiency (WUE), biomass yield (dry mass at anthesis), stress tolerance index (STI) and relative leaf water content (RWC). STI was estimated as described by Fernandez (1992) given by $\mathrm{STI}=\underline{\mathrm{Yp} \mathrm{x} \mathrm{YS}}$ $\left(\mathrm{Yp}^{\prime}\right)^{2}$

Where Yp, Ys and Yp' means biological yield of each genotype in non-stressed environment, biological yield of the genotype in stressed environment and mean biological yield in non-stressed environment. Similarly, WUE was estimated as total water used by each genotype (ml) per

\begin{tabular}{|c|c|c|c|c|c|c|c|}
\hline $\begin{array}{l}\text { S. } \\
\text { No. }\end{array}$ & Genotype & Type* & Source & S.No. & Genotype & Type & Source \\
\hline 1 & BL3791 & Adv. line & NWRP & 31 & BL 3787 & Adv. line & NWRP \\
\hline 2 & Dharwar dry & Cultivar & QDPIF/India & 32 & ABL17 & Adv. line & NWRP \\
\hline 3 & SeriM82 & Cultivar & QDPIF/ CIMMYT & 33 & NPGR 5610 & Landrace & Nepal \\
\hline 4 & Hartog & Cultivar & QDPIF/Australia & 34 & NPGR 5988 & Landrace & Nepal \\
\hline 5 & BL 3798 & Adv. line & NWRP & 35 & NPGR 6001 & Landrace & Nepal \\
\hline 6 & Bhrikuti & Cultivar & NWRP/Nepal & 36 & NPGR 6573 & Landrace & Nepal \\
\hline 7 & BL 3827 & Adv. line & NWRP & 37 & NPGR 6612 & Landrace & Nepal \\
\hline 8 & BL 3845 & Adv. line & NWRP & 38 & NPGR 6696 & Landrace & Nepal \\
\hline 9 & Gautam & Cultivar & NWRP/Nepal & 39 & NPGR 7439 & Landrace & Nepal \\
\hline 10 & BL 3899 & Adv. line & NWRP & 40 & NPGR 7487 & Landrace & Nepal \\
\hline 11 & BL 2800 & Adv. line & NWRP & 41 & NPGR 7504 & Landrace & Nepal \\
\hline 12 & BL 3924 & Adv. line & NWRP & 42 & NPGR 7782 & Landrace & Nepal \\
\hline 13 & BL 3940 & Adv. line & NWRP & 43 & NPGR 7789 & Landrace & Nepal \\
\hline 14 & ABL1 & Adv. line & NWRP & 44 & NPGR 8228 & Landrace & Nepal \\
\hline 15 & ABL2 & Adv. line & NWRP & 45 & NPGR 8232 & Landrace & Nepal \\
\hline 16 & ABL3 & Adv. line & NWRP & 46 & NPGR 8233 & Landrace & Nepal \\
\hline 17 & ABL4 & Adv. line & NWRP & 47 & NPGR 8748 & Landrace & Nepal \\
\hline 18 & ABL5 & Adv. line & NWRP & 48 & NPGR 8749 & Landrace & Nepal \\
\hline 19 & ABL6 & Adv. line & NWRP & 49 & NPGR 8752 & Landrace & Nepal \\
\hline 20 & ABL7 & Adv. line & NWRP & 50 & NPGR 8753 & Landrace & Nepal \\
\hline 21 & ABL8 & Adv. line & NWRP & 51 & NPGR 8762 & Landrace & Nepal \\
\hline 22 & ABL9 & Adv. line & NWRP & 52 & NPGR 8903 & Landrace & Nepal \\
\hline 23 & ABL10 & Adv. line & NWRP & 53 & NPGR 8904 & Landrace & Nepal \\
\hline 24 & ABL11 & Adv. line & NWRP & 54 & NPGR 8911 & Landrace & Nepal \\
\hline 25 & ABL12 & Adv. line & NWRP & 55 & NPGR 9447 & Landrace & Nepal \\
\hline 26 & ABL13 & Adv. line & NWRP & 56 & NPGR 10548 & Landrace & Nepal \\
\hline 27 & ABL14 & Adv. line & NWRP & 57 & NL 1042 & Adv. line & NWRP \\
\hline 28 & ABL15 & Adv. line & NWRP & 58 & BL 3625 & Adv. line & NWRP \\
\hline 29 & ABL16 & Adv. line & NWRP & 59 & Vijaya & Cultivar & NWRP/Nepal \\
\hline 30 & BL3561 & Adv. line & NWRP & 60 & BL3555 & Adv. line & NWRP \\
\hline
\end{tabular}

Table 1. Details of the 60 Wheat Genotypes Included in the Study.

Notes: ${ }^{*}$ Adv. lines $=$ Advanced breeding lines. Pedigree information can be provided upon request by the corresponding author.

NWRP = National Wheat Research Program, QDPIF=Queensland Department of Primary Industries and Fisheries (Australia). 
unit (gm) dry matter. WU was measured by weighing the pot on a weekly interval and WUE was measured by dividing the biomass production from each plant at flowering stage by the total water use.

The RWC was estimated according to Barrs and Weatherley (1962). Briefly, at booting stage flag leaf was excised in morning hours, cut into $12 \mathrm{~cm}$ leaf sections and fresh weight (FW) determined. Then leaf sections were sliced into $2 \mathrm{~cm}$ pieces. $2 \mathrm{~cm}$ pieces and soaked in distilled water for 4 hours. The turgid leaf pieces were then rapidly blotted to remove surface water and weighed to obtain the turgid weight (TW). The sample was dried for 48 hours at $60^{\circ} \mathrm{C}$ in a oven and dry weight (DW) determined. The RWC was calculated using the formula: RWC (\%) $=[($ FW-DW $) /$ (TW-DW)] x 100. All the statistical analysis was performed using the Microsoft Excel, SPSS 16.0 edition and GenStat Discovery edition (VSN International Ltd.).

\section{Results and Discussion}

The analysis of variance (ANOVA) revealed significant variation among the 60 wheat genotypes for all the traits studied (data not shown) and student's ' $t$ ' test confirmed significant mean differences between the two contrasting environments (Table 2). The mean amount of water used (WU) by the genotypes in non stressed environment ranged from 1266 to $2390(\mathrm{ml})$, whereas in drought stressed environment WU ranged between 606 and 880 $\mathrm{ml}$ (Figure1). The genotype vs. moisture regime interaction for WU was highly significant indicating water use pattern of genotypes changed with water availability. This is in conformity with results by Dodig, Zoric et al (2008). BL2800, Gautam; Australian cv. Hartog, and Dharwar dry had higher WU values in non stressed environment in contrast to SeriM82, NPGR6696, Vijay and Bhrikuti which used minimum water during the test period. The biomass production ranged from 3.52 to $17.82(\mathrm{gm})$ in non stressed environment and 3.26 to 7.43 (gm) in moisture stressed environment. The mean biomass produced by the wheat genotypes in moisture stressed environment was significantly lower than that in the non stressed environment. Reduction in biomass due to moisture stress has been reported by Zhu, Liang et al (2008). Under optimum moisture, NPGR 8762, ABL 17 and cv. Gautam had highest biomass. Similarly, in moisture stressed condition, NPGR 8753, NL 1042 and cv. Gautam had maximum biomass. The drought tolerant Indian cultivar Dharwar dry and Nepalese cv. Vijay had average biomass, whereas NPGR 8753, ABL12 and NPGR 8228 had minimum biomass.

\begin{tabular}{|c|c|c|c|c|}
\hline Experiment & $\begin{array}{c}\text { Water } \\
\text { use }(\mathrm{ml})\end{array}$ & $\begin{array}{c}\text { Biomass } \\
(\mathrm{gm})\end{array}$ & $\begin{array}{c}\text { WU Efficiency } \\
\text { (ml/gm dry } \\
\text { wt.) }\end{array}$ & $\begin{array}{l}\text { RWC } \\
(\%)\end{array}$ \\
\hline Optimum moisture & 1856.50 & 12.35 & 178.41 & 73.07 \\
\hline SE (mean) & 34.37 & 0.45 & 40.19 & 1.15 \\
\hline Moisture stressed & 760.60 & 6.57 & 145.03 & 68.47 \\
\hline SE (Mean) & 8.87 & 0.19 & 31.75 & 0.85 \\
\hline Student's t- value & $31.19 * *$ & $11.83 * *$ & $5.05 * *$ & $2.96 *$ \\
\hline
\end{tabular}

Table 2. Significance Test of Environment Means for the Selected Drought Adaptive Traits in 60 Wheat Genotypes.

Notes: *, **; Significant at 0.05 and 0.01 probability levels, respectively.
The water use efficiency (WUE) estimated as total water $(\mathrm{ml})$ transpired per unit dry matter produced $(\mathrm{gm})$ varied from 248.12 to 85.83 and 239.20 to 88.67 in optimum moisture stressed environments, respectively (Figure 2). The expression of WUE was more pronounced in moisture stressed environment. Similar results with improved WUE of winter wheat cultivars grown with limited irrigation has been reported by Zhang, Suib et al (1998) ; Poormohammad Kiani, Grieu et al (2007) in sunflower. In the present study, the most water use efficient wheat genotypes were NPGR 7789, NPGR 6001, ABL7 and ABL3. The popular cv. Gautam was found water use efficient, whereas cv. Bhrikuti, SeriM82 and Dharwar dry were found moderately efficient. The Australian cv. Hartog, NPGR 6573 and Nepalese cv. Vijay were characterized poor in WUE. It is worthwhile to mention that ABL3, NL1O42 and Bhrikuti were highly water use efficient in moisture stressed condition; however, showed a high level of G x E interaction for WUE. Manschadi, Hammer et al (2008) characterized the CIMMYT line SeriM82 and Dharwar dry as drought tolerant and cv. Hartog as a drought sensitive in Australia. The WUE estimated for these genotypes in this experiment also hinted for a similar pattern of drought adaptation (Figure 2).

The relative leaf water content (RWC) of the 60 wheat genotypes in drought stressed environment are presented in Figure 3 which ranged from 45.5 to 82.1 (\%). The genotypes with high RWC under stress were NPGR 8752, Vijaya, BL280o and Gautam. Nepalese cv. Bhrikuti, and Dharwar dry had moderate RWC value. On the other hand, Hartog, SeriM82 and NPGR 8749 had lowest RWC. The latter three genotypes had high ROC value suggesting drought susceptibility (Figure 3). The stress tolerance index (STI) estimated based on biomass produced at anthesis in two contrasting moisture regimes revealed BL280o, NPGR 10548, NPGR 6573, Dharwar dry and Hartog having high STI value (Figure 4). Similarly, cv. Gautam had moderate STI value, whereas, Bhrikuti, Vijaya and SeriM82 had lower STI value.

Water use, water use efficiency, biomass yield and flag leaf relative water content are the important drought tolerancetraits in wheat(Richards, Condon 2002; Rampino, Pataleo et al 2006). Present study revealed a wide range of variability for these traits in Nepalese wheat germplasm, particularly, in landraces and advanced breeding lines. This information can be utilized for wheat improvement for drought stressed environments. Based on the performance of genotypes for all the drought adaptive traits studied and STI index, it was found that cv. Gautam has a number of drought tolerance attributes. As Gautam was identified as high yielding variety under irrigated condition, it's drought adaptive characteristics had not explored during the past study. Water stress damages the number of tiller and then the number of grains per ear, which strongly reduces the yield potential. In addition, the direct selection for grain yield under water stressed condition had been found to be hampered by low heritability, polygenic control, epistasis, and quantitative trait loci by environment interaction (Piepho, 2000). Only the direct screening for yield was done in the past under different moisture regimes however indirect selection in this experiment based on the morphophysiological traits found its robustness in biomass, chlorophyll fluorescence (data not shown in this paper), 


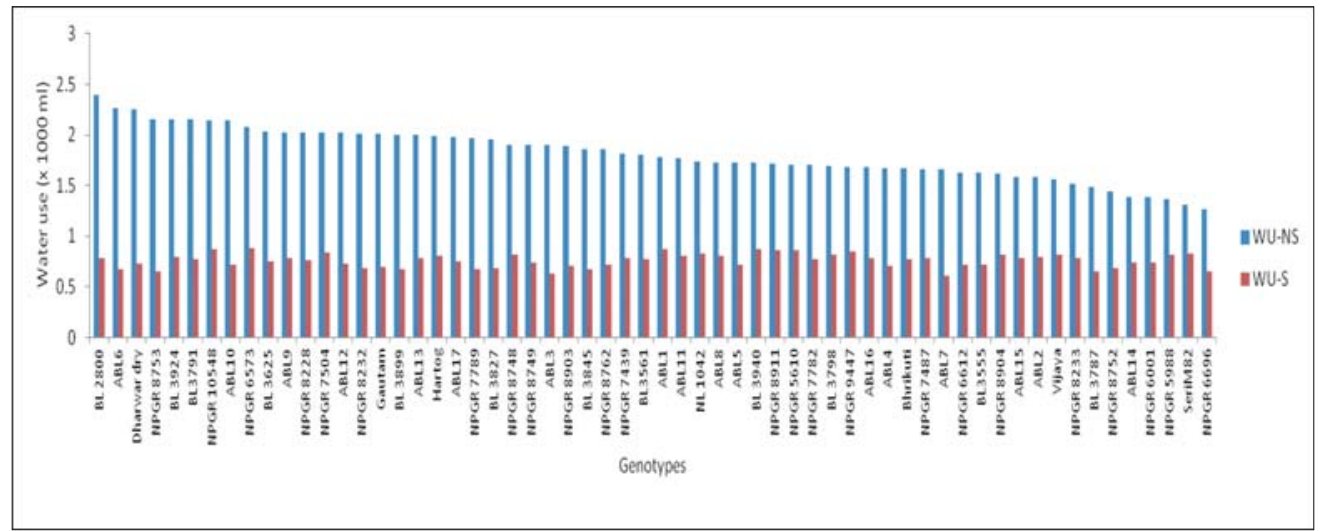

Figure 1. Water Use (ml) by the 60 Wheat Genotypes Measured in Optimum (WU-NS) and Moisture Stressed (WU-S) Experiments. The Genotypes are Arranged ( $L$ to $R$ ) in Decreasing Order of WU Values in Non Stressed Experiment.

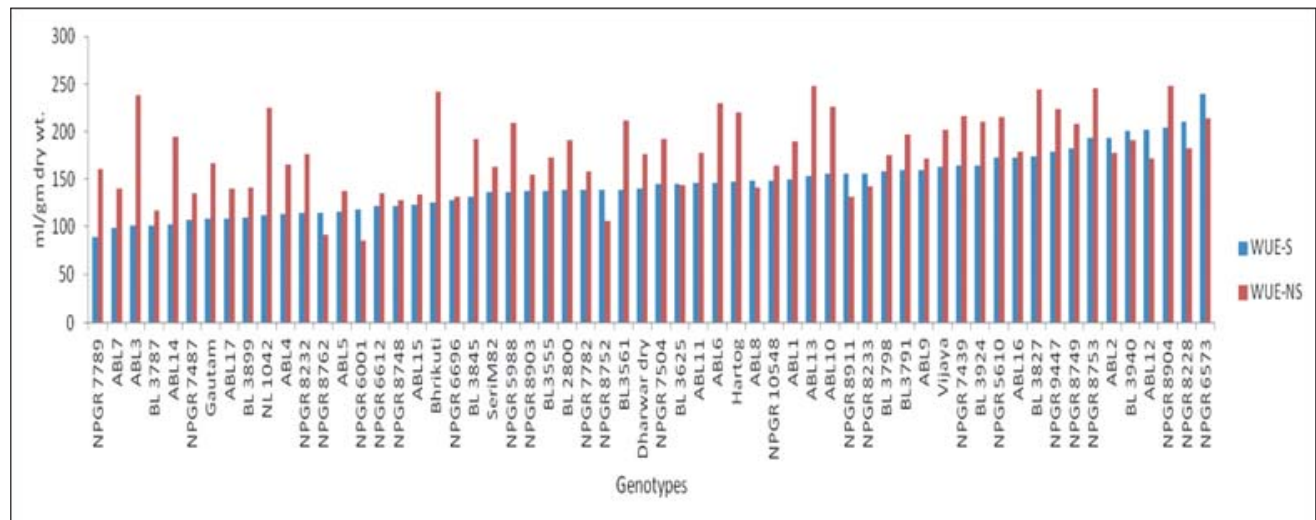

Figure 2. Water Use Efficiency ( $\mathrm{ml} / \mathrm{gm}$ dry wt.) of the 60 Genotypes Assessed in Optimum WUE-NS) and Moisture Stressed (WUE-S) Environments.

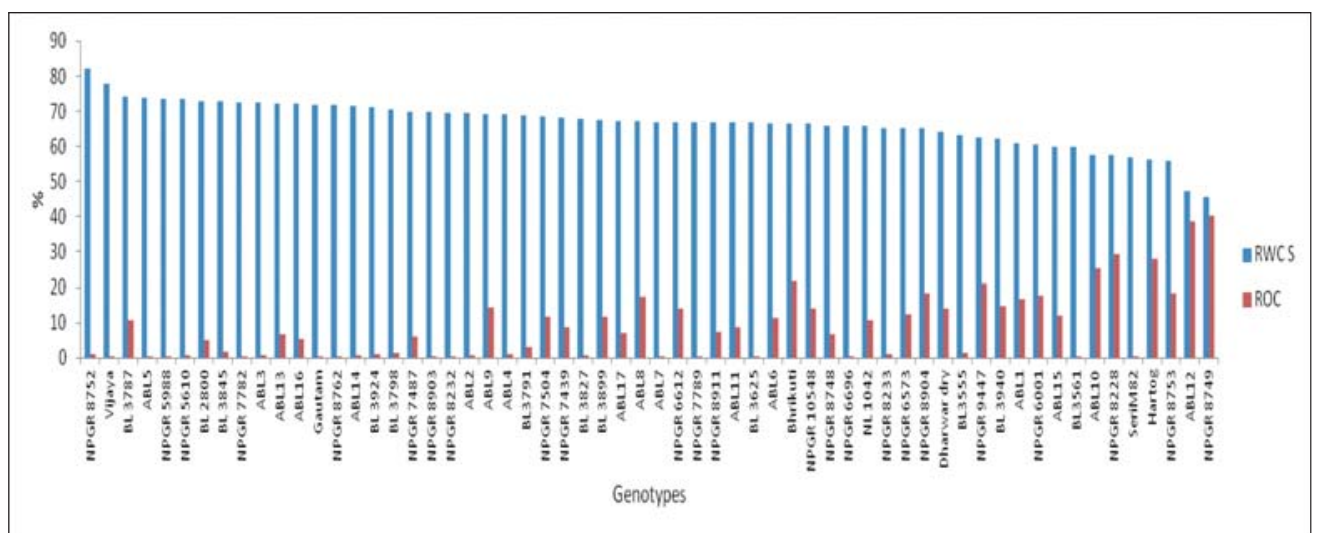

Figure 3. Relative Leaf Water Content (RWC) of the 60 Wheat Genotypes in Moisture Stressed Environment. The Reduction Over Control (ROC) Value for Each Genotype Represents Change in RWC Value in Moisture Stressed Environment Relative to the Non Stressed Environment.

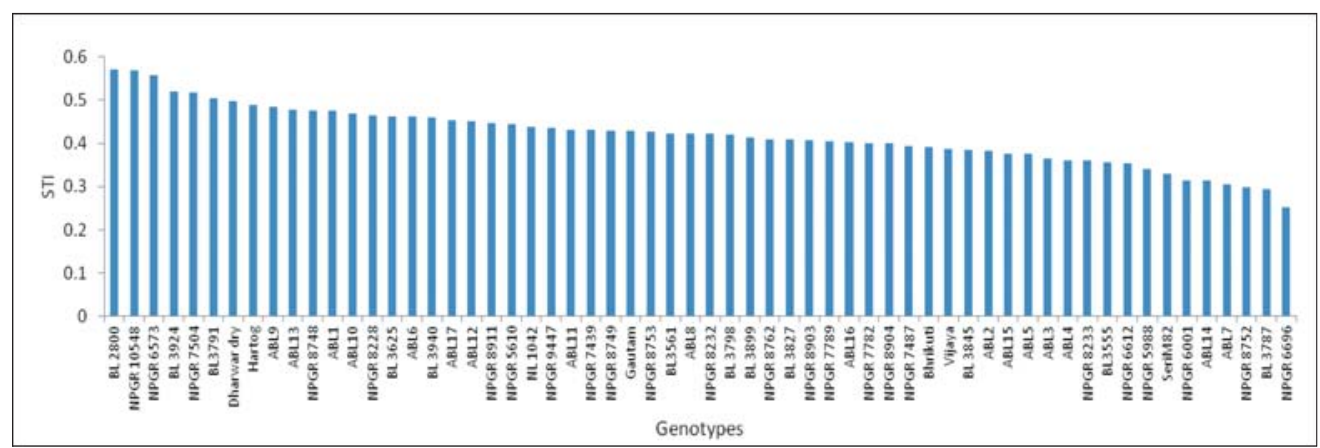

Figure 4. Stress Tolerance Index (STI) Based on Biomass Yield of the 60 Wheat Genotypes Evaluated in Two Contrasting Moisture Regimes. stress tolerance indices, number of tillers, higher water use efficiency than other commercial varieties and made us to conclude that Gautam variety had a number of drought tolerance attributes.

Moreover, Bhrikuti was found average in terms of drought adaptability, whereas, newly released Ug99 resistant cultivar Vijay was characterized as drought sensitive. A number of landraces and advanced breeding lines possessed drought tolerance attributes. Landrace NPGR 7504 is a perspective source of favorable alleles for drought adaptation breeding. As a matter of fact that the present study was based on single plant performance and did not include a full crop cycle as well as grain yield, results are indicative and further experimentation is required to verify the findings.

\section{Acknowledgements}

This work was a part of MSc thesis research of the first author (D. Pokharel). The seed samples provided by the Agricultural Botany Division, Nepal Agricultural Research Council (NARC), National Wheat Research Program, NARC, and Dr. John T. Christopher, Queensland Department of Primary Industries and Fisheries, Leslie Research Centre, Australia, is duly acknowledged. We thank Eiselen Foundation Ulm, Germany, for the financial support to carry out this research.

Dipendra Pokharel is Crop Development Training officer at 
Regional Agriculture Training Center under the Ministry of Agriculture and Co-operatives at Pokhara, Nepal. He holds an MSc Ag degree in Genetics and Plant Breeding from the Institute of Agriculture and Animal Sciences, Rampur, Chitwan, Nepal. He has published research papers and popular articles in national papers. Corresponding address:dgogene@gmail.com

Madhav Pandey is Associate Professor at the Institute of Agriculture and Animal Sciences, Rampur, Chitwan, Nepal. He holds a PhD in Evolutionary Genetics. He is senior plant researcher and has been engaged in drought adaptation research in wheat. Dr Pandey has published over a dozens of papers in national and international journals.

Corresponding address: mppandey@gmail.com

\section{Endnotes}

1. Hartog a CIMMYT developed cultivar popularly known as 'Pavon 76' (released in 17 countries with 17 different names) is known for its drought tolerant as well as one of the major source for durable resistance to leaf and yellow rusts. Seri M84- one of the VEERY cross sister is known for its high yield potential and wide adaptation. The sister lines of VEERY cross were released in different countries with 62 different names.

\section{References}

Barrs, H.D. and P.E. Weatherley, 1962, 'A re-examination of the relative turgidity technique for estimating water deficit in leaves', Australian Journal of Biological Science 15:413-428.

Bhatta, M.R., R.C. Sharma and G. Ortiz-Ferrara, 2008, 'Wheat production and challenges in Nepal', in M.P. Reynolds, J. Pietragalla and H.-J. Braun (eds.), International Symposium on Wheat Yield Potential: Challenges to International Wheat Breeding, Mexico, D.F.: CIMMYT (International Center for Maize and Wheat Improvement).

CIMMYT, 2009, Annual Report, Mexico: CIMMYT.

Dodig, D., M. Zoric, D. Knezevic, S.R. King and G. SurlanMomirovic, 2008, 'Genotype x environment interaction for wheat yield in different drought stress conditions and agronomic traits suitable for selection', Australian Journal of Agricultural Research 59:536-545.

FAOSTAT, 2011, FAOSTAT Homepage; URL: faostat.fao. org.

Fernandez, G.C.J., 1992, 'Effective selection criteria for assessing plant stress tolerance', pp.257-270 in C.G. Kuo (ed.), Proceeding of International Symposium on Adaptation of Vegetables and Other Food Crops to Temperature Water Stress (Tainan, Taiwan, 13-16 August 2011), Tainan, Taiwan: AVRDC (World Vegetable Center).

Foulkes, M.J., R. Sylvester-Bradley, R. Weightman and J.W. Snape, 2007, 'Identifying physiological traits associated with improved drought resistance in winter wheat', Field Crops Research 103(1):11-24.

Joshi, A., B. Mishra, R. Chatrath, G. Ortiz Ferrara and R. Singh, 2007, 'Wheat improvement in India: present status, emerging challenges and future prospects', Euphytica 157(3):431-446.
Kisana, N.S., I. Hussain, M.Y. Mujahid and S.Z. Mustafa, 2008, 'Increasing wheat productivity in Pakistan', in M.P. Reynolds, J. Pietragalla and H.-J. Braun (eds.), International Symposium on Wheat Yield Potential: Challenges to International Wheat Breeding, Mexico, D.F.: CIMMYT (International Center for Maize and Wheat Improvement).

Kosina, P., M. Reynolds, J. Dixon and A. Joshi, 2007, 'Stakeholder perception of wheat production constraints, capacity building needs, and research partnerships in developing countries', Euphytica 157(3):475-483.

Manschadi, A.M., G.L. Hammer, J.T. Christopher and P. deVoil, 2007, 'Genotypic variation in seedling root architectural traits and implications for drought adaptation in wheat (Triticum aestivum L.)', Plant and Soil 303:115-129.

MOAC, 2010, Statistical Information on Nepalese Agriculture, Kathmandu: Ministry of Agriculture and Cooperatives/Agri-Business Promotion and Statistics Division.

Piepho, H.P., 2000, 'A mixture-model approach to mapping quantitative trait loci in barley on the basis of multiple environment data', Genetics 156:2043-2050.

Poormohammad Kiani, S., P. Grieu, P. Maury, T. Hewezi, L. Gentzbittel and A. Sarrafi, 2007, 'Genetic variability for physiological traits under drought conditions and differential expression of water stress-associated genes in sunflower (Helianthus annuus L.)', Theoretical and Applied Genetics 114(2):193-207.

Rampino, P., S. Pataleo, C. Gerardi, G. Mita and C. Perrotta, 2006, 'Drought stress response in wheat: physiological and molecular analysis of resistant and sensitive genotypes', Plant Cell Environment 29:2143-2152.

Richards, R.A., A.G. Condon and G.J. Rebetzkel, 2001, 'Traits to improve yield in dry environments', pp.88-100 in M.P. Reynolds, J.I. Ortiz-Monasterio and A. McNab (eds.). Application of Physiology in Wheat Breeding, Mexico, D.F.: CIMMYT (International Center for Maize and Wheat Improvement).

Richards, R.A., G.J. Rebetzke, A.G. Condon and A.F. Herwaarden, 2002, Breeding opportunities for increasing the efficiency of water use and crop yield in temperate cereals. Crop Science, 42:111-121.

Trethowan, R. and W.H. Pfeiffer, 2000, 'Challenges and future strategies in breeding wheat for adaptation to drought stressed environments: A CIMMYT wheat program perspective', pp.45-48 in J.M. Ribaut and D. Poland (eds.), Molecular Approaches for the Genetic Improvement of Cereals for Stable Production in Water Limited Environments: A CIMMYT Wheat Program Perspective, Mexico, D.F.: CIMMYT (International Center for Maize and Wheat Improvement).

Zhang, J., X. Suib, B. Lib, B. Sub, J. Lib and D. Zhoub, 1998, 'An improved water-use efficiency for winter wheat grown under reduced irrigation', Field Crops Research 59(2):91-98.

Zhu, L., Z.S. Liang, X. Xu, S.H. Li, J.H. Jing and P. Monneveux, 2008, 'Relationships between carbon isotope discrimination and leaf morphophysiological traits in spring-planted spring wheat under drought and salinity stress in Northern China', Australian Journal of Agricultural Research 59:941-949. 